\title{
Detection of Breast Cancer 1 (BRCA1) Gene Using an Electrochemical DNA Biosensor Based on Immobilized Zn0 Nanowires
}

\author{
Nur Azimah Mansor'1, Zainiharyati Mohd Zain', Hairul Hisham Hamzah"1, \\ Mohd Shihabuddin Ahmad Noorden ${ }^{2,3}$, Siti Safura Jaapar ${ }^{2}$, Valerio Beni', \\ Zafar Husain Ibupoto 5 \\ ${ }^{1}$ Faculty of Applied Sciences, Universiti Teknologi MARA, Shah Alam, Malaysia \\ ${ }^{2}$ Faculty of Pharmacy, Universiti Teknologi MARA, Puncak Alam, Malaysia \\ ${ }^{3}$ Atta-ur-Rahman Institute for Natural Product Discovery, Universiti Teknologi MARA, Puncak Alam, Malaysia \\ ${ }^{4}$ Biosensors and Bioelectronics Centre, Department of Physics, Chemistry, and Biology, Linköping University, \\ Linköping, Sweden \\ ${ }^{5}$ Physical Electronics and Nanotechnology Division, Department of Science and Technology (ITN), \\ Campus Norrköping, Linköping University, Norrköping, Sweden \\ Email: zainihar@salam.uitm.edu.my
}

Received 14 February 2014; revised 1 April 2014; accepted 8 April 2014

Copyright (C) 2014 by authors and Scientific Research Publishing Inc.

This work is licensed under the Creative Commons Attribution International License (CC BY).

http://creativecommons.org/licenses/by/4.0/

(c) (i) Open Access

\section{Abstract}

Herein we report an electrochemical DNA biosensor for the rapid detection of sequence (5' AAT GGA TTT ATC TGC TCT TCG 3') specific for the breast cancer 1 (BRCA1) gene. The proposed electrochemical genosensor is based on short oligonucleotide DNA probe immobilized onto zinc oxide nanowires (ZnONWs) chemically synthesized onto gold electrode via hydrothermal technique. The morphology studies of the ZnONWs, performed by field emission scanning electron microscopy (FESEM), showed that the ZnO nanowires are uniform, highly dense and oriented perpendicularly to the substrate. Recognition event between the DNA probe and the target was investigated by differential pulse voltammetry (DPV) in $0.1 \mathrm{M}$ acetate buffer solution (ABS), pH 7.00; as a result of the hybridization, an oxidation signal was observed at $+0.8 \mathrm{~V}$. The influences of $\mathrm{pH}$, target concentration, and non-complimentary DNA on biosensor performance were examined. The proposed DNA biosensor has the ability to detect the target sequence in the range of concentration between 10.0 and 100.0 $\mu \mathrm{M}$ with a detection limit of $3.32 \mu \mathrm{M}$. The experimental results demonstrated that the prepared ZnONWs/Au electrodes are suitable platform for the immobilization of DNA.

\section{Keywords}

Zinc Oxide Nanowires, DNA Biosensor, Breast Cancer Gene, BRCA1, DNA Hybridization, Differential 


\section{Pulse Voltammetry}

\section{Introduction}

Breast cancer, that affects mainly inner lining of milk ducts, is one of the major causes of death of our times. Distant metastases are regarded as the major reason of death, so an early stage diagnosis, and subsequently treatment, of the cancer is highly required [1]. Breast cancer has been associated to various gene mutations but the most common mutations, all associated to the activation of breast cancer cells, are BRCA1, BRCA2 and p53 which occurred in the error-correcting mechanisms. These mutations are either inherited or acquired after birth and usually they promote other mutations, which led to increasing speed in cells division, lack of attachment and metastasis to distant organs [2] [3]. Breast cancer 1 (BRCA1) is a tumor suppressor gene where the BRCA1 protein is involved in the prevention of fast and uncontrolled growth of cells. Mutations in this gene make the BRCA1 protein unable to repair damaged DNA leading in this way cells to grow uncontrollably and form tumor. The BRCA1 gene was identified in 1994; this is located in the region from 38.449.840 to 38.530.994 based pair on band 21 of the chromosome 17 [4]. This gene is responsible for $40 \%$ of risk of breast cancers to the carrier [5] [6]. Subsequently, these point mutations have been proposed as possible biomarkers in the early detection and screening of breast cancer.

Ultimately site specific sensing platforms are strongly needed for early detection of breast cancer gene during biopsy. This is due to the fact that the existing nucleic acid (DNA) detection techniques, as northern blotting, ribonuclease protection assays, reverse transcription-polymerase chain reaction (RT-PCR) and DNA sequencing have several limitations, including low sensitivity, poor selectivity, expensive and nonlinearity to the target strength [7] [8]. Therefore, highly specific, rapid, inexpensive and convenient breast cancer gene detection systems will be required to support clinician for monitor early disease progressions of disease in suspected individuals. This will also allow that a more appropriate cancer treatment can be planned out to minimize toxicity according to the specific tumor cell type [9]. The development of DNA based sensing can be an alternative screening to a guide treatment. In recent years, electrochemical DNA biosensors have received much attention providing simple, accurate and rapid responses, high sensitivity, inherent selectivity, and being inexpensive platform for molecular detection [10].

Biosensor is a compact analytical device having a biological recognition element intimately integrated with a physio-chemical transducer. The three main components of a biosensor are: the biological recognition elements such as enzyme, DNA, antibody, and nucleic acid, the transducer that converts the biological recognition event into a quantifiable signal and finally the signal processing system. The five principle transducer classes are optical, thermometric, electrochemical, piezoelectric, and magnetic. Electrochemical transduction due to its better sensitivity, selectivity, reproducibility, and easy maintenance as well as low cost, has gained a lot of popularity in DNA biosensors [11]-[13]. Electrochemical biosensors also played an important role in the transition towards point-of-care diagnostic device as demonstrated by the world wide distributed glucosensors.

The basic principle of DNA biosensor usually relies on the immobilization of single stranded oligonucleotide (ssDNA) probe on the surface of an electrode providing; in this way the specificity towards a specific target DNA. Recognition event, based on DNA hybridization, is then converted into readable signal by transducer.

The performance of an electrochemical genosensor relies heavily on the properties of the supporting materials; these should provide a good environment for DNA immobilization, without compromising its biological activity, and providing good transduction abilities [14]. Currently the use of nanomaterials in the biosensor field has become one of the top research interests among the scientific community due to the fact that these offer many advantages, such as large surface-to-volume ratio, high surface reaction activity and fast electron communication. Subsequently the electrochemical sensor designed around them has been shown to have low limit of detection and to allow detection of analyte from small volumes [15]. Moreover, the coupling of electrochemical devices and nanoscale materials offers a unique multiplexing capability for simultaneous measurements of multiple bio-markers [10]. Among these nanomaterials, zinc oxide $(\mathrm{ZnO})$ nanostructures provide a solid platform for the biosensing. ZnO exhibits excellent properties for the fabrication of biosensors, such as good biocompatibility, chemical stability, non-toxicity, and fast electron transfer rate [16]. Most of all, the $\mathrm{ZnO}$ behaves as an excellent transducer because of its high isoelectric point (IEP) value, approximately 9.5, that facilitates the immobilization 
of low isoelectric IEP DNA or proteins [17]. Among many nano-structured $\mathrm{ZnO}$, the $\mathrm{ZnO}$ nanowires (ZnONWs) have been widely studied for the immobilization of biomolecules [18]. These nanostructures present some unique chemical and physical properties caused by nanoscale effect which provide new opportunities for the developing of DNA biosensor.

Recently, reports on electrochemical genosensors for the detection of breast cancer genes and cells have been reported [19] [20]. However, up to date, the developer of DNA biosensor for the detection of breast cancer gene (BRCA1) based on modified gold electrode has not yet reported. The main objective of the work reported herein was to demonstrate that $\mathrm{ZnO}$ nanowires, chemically grown onto Au substrate, could provide a suitable platform for the development of electrochemical DNA biosensor for the detection of (BRCA1) gene. Furthermore this concept could be further elaborated into array format for the multiplexed detection of other breast cancer genes such as BRCA2, and p53 and can also be applied on real samples of breast cancer cells.

\section{Experimental}

\subsection{Instrumentation}

Electrochemical measurements were performed at room temperature using AUTOLAB-PGSTAT 302N (Echo Chemie, The Netherlands). The three electrodes electrochemical systems consisted of: ZnONWs/Au as working electrode, a platinum wire as auxiliary electrode, and an $\mathrm{Ag} / \mathrm{AgCl}$ as reference electrode. The DPV were performed in $15 \mathrm{~mL}$ of $0.1 \mathrm{M}$ acetate buffer solution (ABS) (pH 7.00) from $0.4 \mathrm{~V}$ to $1.16 \mathrm{~V}$ with a modulation amplitude $=0.025 \mathrm{~V}$, an interval time $(\mathrm{t} 1)=0.5 \mathrm{~s}$, modulation time $(\mathrm{t} 2)=0.05 \mathrm{~s}$, step potential $=0.005 \mathrm{~V}$ and a scan rate of $0.01 \mathrm{Vs}^{-1}$. The acetate buffer solution was purged with nitrogen gas for 20 min prior to each experiment. The $\mathrm{ZnONWs/Au} \mathrm{electrode} \mathrm{surface} \mathrm{was} \mathrm{characterized} \mathrm{by} \mathrm{field} \mathrm{emission} \mathrm{scanning} \mathrm{electron} \mathrm{microscope}$ (FESEM).

\subsection{Reagents}

Zinc nitrate hexahydrate, $\mathrm{Zn}\left(\mathrm{NO}_{3}\right)_{2} \cdot 6 \mathrm{H}_{2} \mathrm{O}$, hexamethylenetetramine, $\mathrm{C}_{6} \mathrm{H}_{12} \mathrm{~N}_{4}$, and zinc acetate dehydrate, $\mathrm{Zn}$ $\left(\mathrm{CH}_{3} \mathrm{COO}\right)_{2} \cdot 2 \mathrm{H}_{2} \mathrm{O}$ were purchased from Sigma Aldrich, Germany. The 21-base pair single stranded DNAs were purchased from First BASE (IDT Inc, USA). The sequences of the different oligonucleotide are as follows (underlined are the mismatched bases):

Probe DNA: 5’ AAT GGA TTT ATC TGC TCT TCG 3'

Target DNA: 5' CGA AGA GCA GAT AAA TCC ATT 3'

Three-base mismatch: 5' CGA AGA GGA GA스 AAA TCG ATT 3'; 5' CAA AGA GCA GAT AGA TCC GTT 3'

The oligonucleotide stock solutions $(100 \mu \mathrm{M})$ were prepared with deionized water and stored at $4{ }^{\circ} \mathrm{C}$ when not in use. Acetate buffer solution (ABS) of $0.1 \mathrm{M}$ concentration with different $\mathrm{pH}$ values were prepared by mixing different volumes of $0.1 \mathrm{M}$ acetic acid and sodium acetate with deionized water.

\subsection{Synthesis of Zinc Oxide Nanowires (ZnONWs) onto the Surface of Gold Electrode}

The growth of $\mathrm{ZnO}$ nanowires was performed by hydrothermal method. Firstly, a gold electrode/substrate on silicon wafer purchased from Sigma Aldrich, Stockholm, Sweden was cleaned with isopropanol, washed with deionized water and finally dried at room temperature. As first step of the synthesis, a seed layer of zinc acetate dihydrate was prepared by spin coated for three times at 2500 r.p.m for $30 \mathrm{~s}$ onto the gold substrate. Following spin coating the substrate was annealed at $120^{\circ} \mathrm{C}$ for $10-20$ mins. The seed particles containing electrodes were affixed onto a Teflon sample holder and then immersed in the growth solution of $(0.075 \mathrm{M})$ zinc nitrate hexahydrate and $(0.075 \mathrm{M})$ hexamethylenetetramine at $98^{\circ} \mathrm{C}$ for 9 hours. After the growth of $\mathrm{ZnO}$ is completed, the grown nanostructures were washed with deionized water in order to remove eventual residual particles. Finally the $\mathrm{ZnONWs/Au} \mathrm{electrodes} \mathrm{were} \mathrm{left} \mathrm{to} \mathrm{dry} \mathrm{at} \mathrm{room} \mathrm{temperature.}$

\subsection{Immobilization of Probe ssDNA onto the Surface of ZnONWs/Au Electrode}

$40 \mu \mathrm{L}$ containing $80 \mu \mathrm{M}$ of ssDNA molecules (probe) were drop casted onto the ZnONWs/Au electrode. The ssDNA molecules were left for immobilization onto ZnO NWs/Au electrode for 2 hours. Following the prepared electrodes were rinsed with ABS for $5 \mathrm{~s}$ to remove the unbound probes. The resulting electrode was labeled as 
ssDNA/ZnONWs/Au.

\subsection{Hybridization of SSDNA}

Hybridization assay was performed by spotting onto the sensor surface $40 \mu \mathrm{L}$ of a solution containing the desired concentration, $80 \mu \mathrm{M}$ of the complementary ssDNA, mismatches ssDNA and non-complementary ssDNA respectively. The hybridization was left to take place for $30 \mathrm{~min}$.; following the electrode was then rinsed with ABS for $5 \mathrm{~s}$ to remove the non-hybridized targets ssDNA.

\section{Results and Discussion}

\subsection{Morphologies of ZnONWs Modified Gold Electrode and Immobilized ssDNA onto the Surface of ZnONWs Modified Gold Electrode}

In Figure 1(A) a typical FESEM image of the successfully hydrothermally grown ZnONWs onto gold surface electrode is presented. It is clearly seen that the overall grown $\mathrm{ZnONWs}$ are highly dense and vertically aligned with hexagonal faces to the surface of gold electrode. In addition, the size of the nanohexagones was estimated to be in the range between 450 and $550 \mathrm{~nm}$ with uniform density and spatial distribution. In principle, the diameter and length of grown $\mathrm{ZnONWs}$ can be tuned by a fine control over the growth process parameters such as the concentration of seed solution, the reagent stoichiometry, the temperature, and the $\mathrm{pH}$ of the growth solution [21] [22]. Moreover, the FESEM image following the immobilization of the ssDNA probe is shown in Figure 1(B). As clearly shown in this figure, the immobilization of the ssDNA onto the ZnONWs modified electrode resulted in a homogenous coverage. It can be concluded that the ZnONWs structure provided a good platform for the immobilization of the ssDNA.

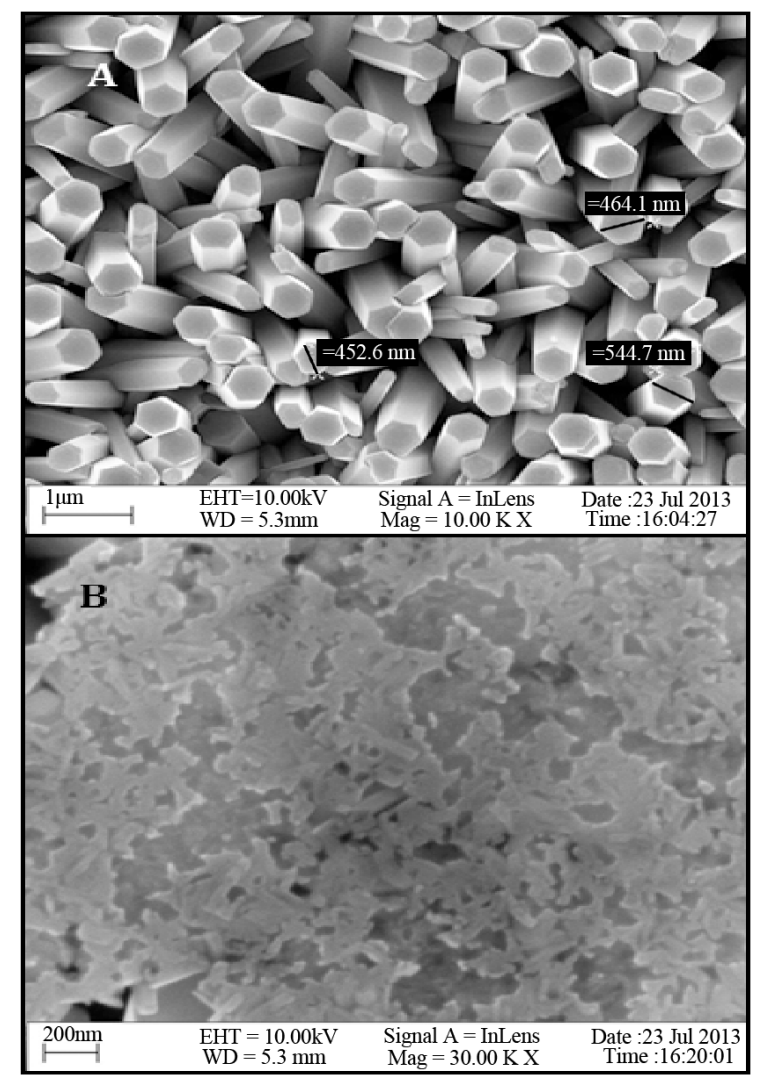

Figure 1. FESEM image of grown zinc oxide nanowires (ZnONWs) at the surface of gold electrode (A), and immobilized ssDNA onto the surface ZnONWs modified gold electrode (B). 


\subsection{Conformation of Immobilization of Probe ssDNA and Hybridization of Target ssDNA onto the ZnO NWs Modified Gold Electrode.}

The hybridization of the immobilized ssDNA probe with the complementary ssDNA (target) was studied by differential pulse voltammetry. Figure 2 shows the DPV responses obtained for different sensing surfaces (curves c, e and f) and after hybridization with different DNA targets (curves a, b and d). No visible peaks were recorded when DPV were conducted at Au electrode (curve f); on the other hand when voltammetric measurements were performed onto the ZnONWs/Au electrode modified with the ssDNA (as from section 2.4) a clear oxidation peak at $0.94 \mathrm{~V}$ and a shoulder at ca. $0.62 \mathrm{~V}$ were recorded. These two peaks were probably associated with the oxidation of the Adenine and Guanine $(0.94 \mathrm{~V})$ bases of the DNA probe. As it can be observed from curve a, the hybridization with the complementary target resulted in a large broader peak at ca. $0.8 \mathrm{~V}$ [23] [24]. No peaks were recorded when hybridization were performed with mismatched sequences (curves b and d) confirming the specificity of the developed genosensor. Furthermore, as from curve c, this proved that the presence of the ssDNA probe is crucial to perform DNA hybridation with its target because we observed no electrochemical response in its absence. The results presented above indicated that the hybridization process at the developed sensor surface is very selective which took place only in the presence of fully complementary target. On top of that, a significant electrochemical response was recorded when complementary DNA is hybridized onto the sensor surface.

\subsection{Effect of DNA Target Loading on DNA Biosensor Response}

Figure 3 represents the DNA biosensor response with various concentrations of DNA target, hybridized for 90 min. at the sensor surface. Well defined hybridization signals were observed over the concentration range of 10 $100 \mu \mathrm{M}$ of target DNA. Upon further increase of target concentration $(>100 \mu \mathrm{M})$, the hybridization of DNA signal slightly decreased indicating that the saturation of surface has been reached. Thus, $100 \mu \mathrm{M}$ was chosen as the optimum target concentration on the hybridization reaction of immobilized ssDNA at the surface of ZnO NWs/Au electrode. This is attributed to full surface coverage of $\mathrm{ZnONWs/Au}$ electrode at this concentration.

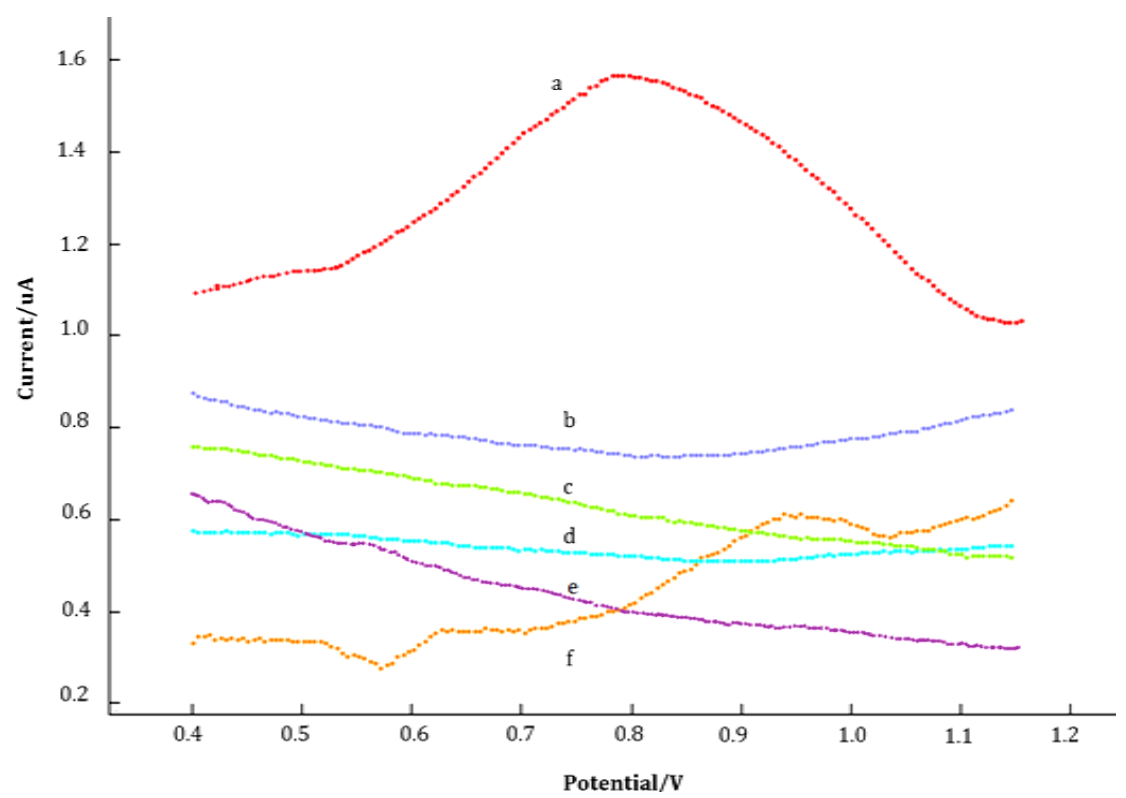

Figure 2. Differential pulse voltamograms (DPVs) that were obtained from immobilization of $80 \mu \mathrm{M}$ ssDNA onto the surface of ZnONWs modified gold electrode after the probes were exposed to $100 \mu \mathrm{M}$ complimentary or target DNA (a), 3 mismatches or non-complimentary ssDNA (b) and (d), without ssDNA immobilization (c), for bare gold electrode (e) and ZnO NWs modified gold electrode-ssDNA (f). The DPVs were measured at a potential scanned between 0.4 to $1.16 \mathrm{~V}$ with a modulation amplitude = $0.025 \mathrm{~V}$, interval time $(\mathrm{t} 1)=0.5 \mathrm{~s}$, modulation time $(\mathrm{t} 2)=0.05 \mathrm{~s}$ and step potential $=$ $0.005 \mathrm{~V}$ in $0.1 \mathrm{M}$ acetate buffer solution at $\mathrm{pH} 7$. 


\subsection{Dependence of Biosensor Response on $\mathrm{pH}$}

Figure 4 illustrates the effect of $\mathrm{pH}$ on the response of the sensor. In this set of experiments the genosenor prepared according to the protocol described in section 2.4 was hybridized for $90 \mathrm{~min}$. with $80 \mu \mathrm{M}$ and DPV response recorded for different $\mathrm{pH}$ values. The recorded response presented a maximum at $\mathrm{pH} 7$ indicating the optimal $\mathrm{pH}$ for DNA detection. The increased response of DNA biosensor at $\mathrm{pH} 7$ can be described to a more efficient hybridization process. At more acidic condition, the protonation reaction of the phosphodiester of the DNA can reduce the solubility of the DNA molecule, which eventually decreases the DNA hybridization. In addition, under a more basic medium, decreases of DNA hybridization process occurred and therefore; a tendency to produce a lower DPV current.

\subsection{Calibration Characteristic and the Stability of DNA Biosensor}

Figure 5 demonstrates the effect of different complementary DNA concentrations on the biosensor response. The linear response was obtained when the BRCA1 concentrations is within the range of $10-100 \mu \mathrm{M}$. The current response increased linearly $\left(\mathrm{R}^{2}=0.994\right)$ with a sensitivity of $6.36 \mu \mathrm{A} \cdot \mu \mathrm{M}^{-1}$ whereas bare gold electrode showed lower sensitivity $\left(1.97 \mu \mathrm{A} \cdot \mu \mathrm{M}^{-1}\right)$. The limit of detection (LOD) of BRCA1 of the developed biosensor-based ZnONWs modified gold electrode, calculated as the signal of the blank plus three time the standard deviation [25], was found to be $3.32 \mu \mathrm{M}$. An estimate LOD of $3.79 \times 10^{-7} \mathrm{M}$ was reported by $\mathrm{Li}$ and co-workers [3] for the label free DNA hybridization for BRCA1 based upon single walled carbon nanotube modified screen printed graphite electrodes. This can be understood that the application of ZnONWs on our modified gold electrode for DNA hybridization to the target of BRCA1 tends to give a great sensitivity in our developed biosensor.

\section{Conclusions}

The ZnONWs modified gold electrode revealed to be an excellent electrode substrate for the development of a sensitive DNA biosensor for the detection of breast cancer gene BRCA1. The FESEM image showed that nanostructure has been successfully grown at the surface of the gold electrode with an average diameter between 450 - $550 \mathrm{~nm}$ and with a good orientation. Furthermore we demonstrated that direct electrochemistry of DNA via the use of DPV measurement, was suitable for the selective detection of short DNA sequence associated with the BRCA1 gene, when DNA probes were chemisorbed onto the ZnONWs/Au surface. Presence of complementary DNA sequence resulted in a well-defined oxidation peak at ca. $0.8 \mathrm{~V}$. The optimized $\mathrm{pH}$ condition for DNA biosensor operation was at $\mathrm{pH}$ 7. The response of the developed DNA biosensor was linear within complimentary target concentrations in between of $10-100 \mu \mathrm{M}$. In addition, the LOD was obtained on the li-

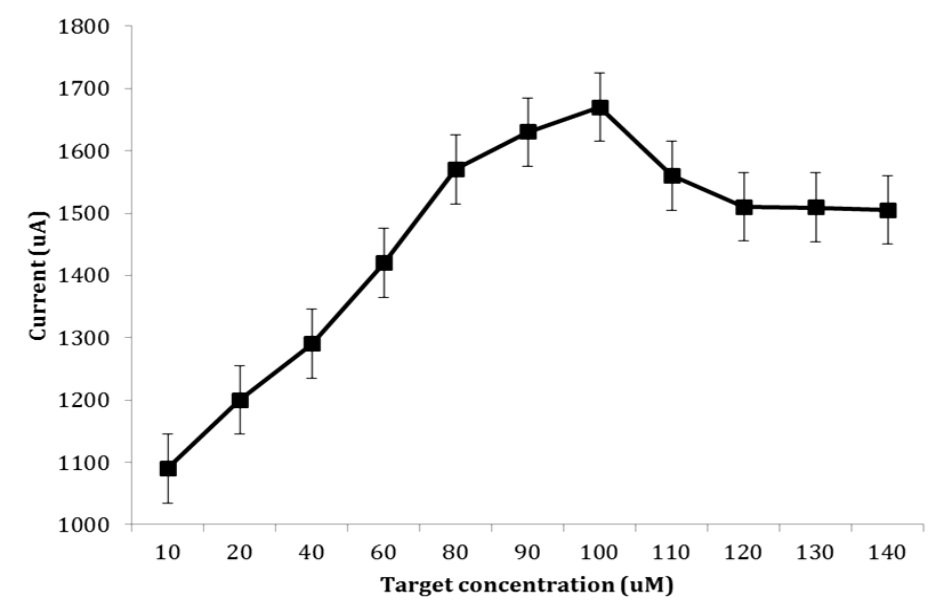

Figure 3. Current produced from DNA hybridization of $80 \mu \mathrm{M}$ immobilized ssDNA on ZnONWs modified gold electrode to its target (BRCA1) in various concentrations (10 to $120 \mu \mathrm{M})$. The signal of DPV currents were measured at a potential scanned between 0.4 to $1.16 \mathrm{~V}$ with a modulation amplitude $=0.025 \mathrm{~V}$, interval time $(\mathrm{t} 1)=0.5 \mathrm{~s}$, modulation time $(\mathrm{t} 2)=0.05 \mathrm{~s}$ and step potential $=0.005 \mathrm{~V}$ in $0.1 \mathrm{M}$ acetate buffer solutions ( $\mathrm{pH} 7)$. 


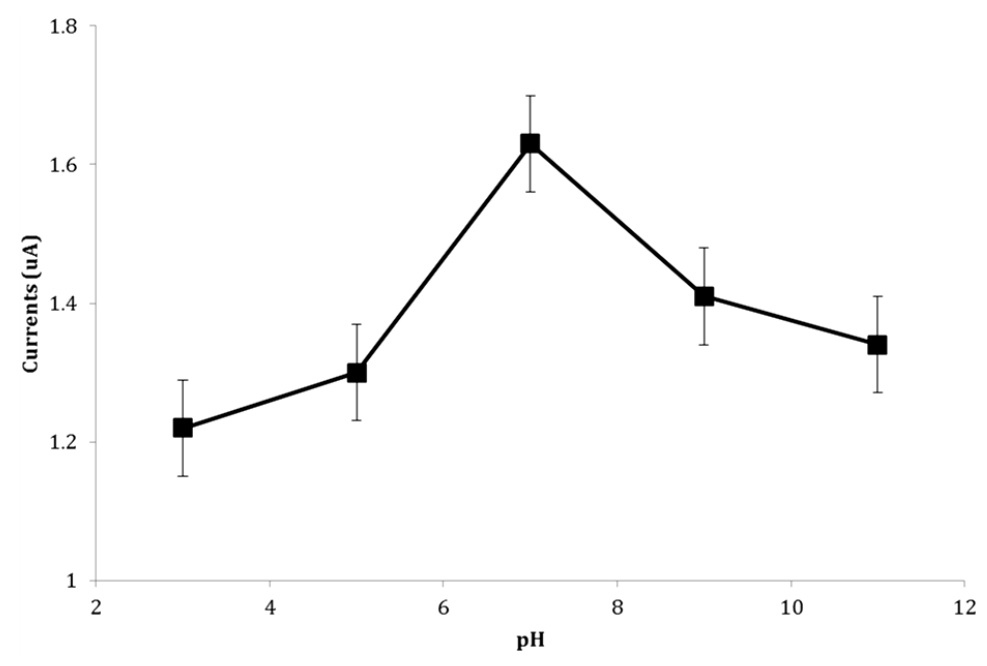

Figure 4. The $\mathrm{pH}$ effect on the biosensor response as indicated by the hybridization current with complementary DNA in $0.1 \mathrm{M}$ ABS. The signal of DPV currents were measured at a potential scanned between 0.4 to $1.16 \mathrm{~V}$ with a modulation amplitude $=0.025 \mathrm{~V}$, interval time $(\mathrm{t} 1)=0.5 \mathrm{~s}$, modulation time $(\mathrm{t} 2)=0.05 \mathrm{~s}$ and step potential $=0.005 \mathrm{~V}$ in $0.1 \mathrm{M}$ buffer solutions $(\mathrm{pH}$ 3-11).

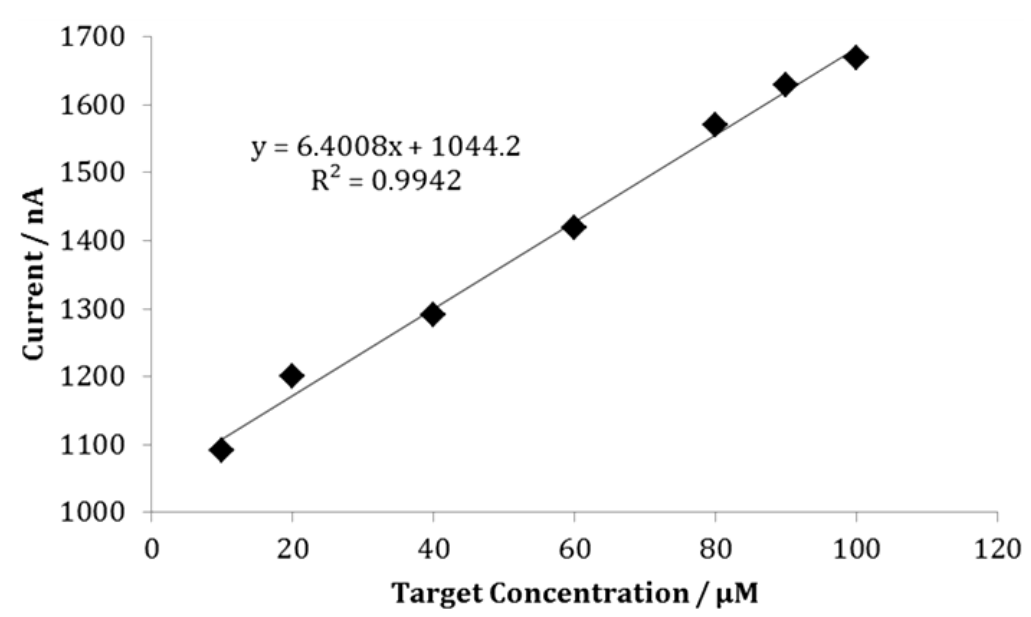

Figure 5. Calibration plot presenting the changes of oxidation signals measured in the presence of DNA hybridization between $80 \mu \mathrm{M}$ BRCA1 probe and various concentration levels of BRCA1 targets. The signal of DPV currents were measured at a potential scanned between 0.4 to $1.16 \mathrm{~V}$ with a modulation amplitude $=0.025 \mathrm{~V}$, interval time $\left(\mathrm{t}_{1}\right)=0.5 \mathrm{~s}$, modulation time $\left(\mathrm{t}_{2}\right)=0.05 \mathrm{~s}$ and step potential $=0.005 \mathrm{~V}$ in $0.1 \mathrm{M}$ buffer solutions ( $\mathrm{pH} 7)$.

near response of developed method, which was found to be $3.32 \mu \mathrm{M}$.

\section{Acknowledgements}

We would like to thank the Ministry of Higher Education Malaysia for the ERGS grant (600/RMI/st/ERGS/ 5/3/fst12/2011) and Universiti Teknologi MARA for financial support via postgraduate teaching assistant scheme (UPTA) to Nur Azimah Mansor for conducting this research.

\section{References}

[1] Li, T., Fan, Q., Liu, T., Zhu, X., Zhao, J. and Li, G. (2010) Detection of Breast Cancer Cells Specially and Accurately 
by an Electrochemical Method. Biosensors and Bioelectronics, 25, 2686-2689. http://dx.doi.org/10.1016/j.bios.2010.05.004

[2] Dolatabadi, J.E.N., Mashinchian, O., Ayoubi, B., Jamali, A.A., Mobed, A., Losic, D., et al. (2011) Optical and Electrochemical DNA Nanobiosensors. TrAC Trends in Analytical Chemistry, 30, 459-472. http://dx.doi.org/10.1016/j.trac.2010.11.010

[3] Antoniou, A., Pharoah, P.D.P., Narod, S., Risch, H.A., Eyfjord, J.E., Hopper, J.L., et al., (2003) Average Risks of Breast and Ovarian Cancer Associated with BRCA1 or BRCA2 Mutations Detected in Case Series Unselected for Family History: A Combined Analysis of 22 Studies. The American Journal of Human Genetics, 72, 1117-1130. http://dx.doi.org/10.1086/375033

[4] Li, C.-Z., Karadeniz, H., Canavar, E. and Erdem, A. (2012) Electrochemical Sensing of Label Free DNA Hybridization Related to Breast Cancer 1 Gene at Disposable Sensor Platforms Modified with Single Walled Carbon Nanotubes. Electrochimica Acta, 82, 137-142. http://dx.doi.org/10.1016/j.electacta.2012.05.057

[5] Kamb, A., Futreal, P.A., Rosenthal, J., Cochran, C., Harshman, K.D., Liu, Q., et al., (1994) Localization of the VHR Phosphatase Gene and Its Analysis as a Candidate for BRCA1. Genomics, 23, 163-167. http://dx.doi.org/10.1006/geno.1994.1473

[6] Culha, M., Stokes, D.L., Griffin, G.D. and Vo-Dinh, T. (2004) Application of a Miniature Biochip Using the Molecular Beacon Probe in Breast Cancer Gene BRCA1 Detection. Biosensors and Bioelectronics, 19, 1007-1012. http://dx.doi.org/10.1016/j.bios.2003.09.006

[7] Tiwari, A. and Gong, S. (2009) Electrochemical Detection of a Breast Cancer Susceptible Gene Using cDNA Immobilized Chitosan-co-Polyaniline Electrode. Talanta, 77, 1217-1222. http://dx.doi.org/10.1016/j.talanta.2008.08.029

[8] Yin, H., Xu, Z., Wang, M., Zhang, X. and Ai, S. (2013) An Electrochemical Biosensor for Assay of DNA Methyltransferase activity and screening of inhibitor. Electrochimica Acta, 89, 530-536. http://dx.doi.org/10.1016/j.electacta.2012.11.093

[9] Elzouki, A.-N., El-Menyar, A., Ahmed, E., Elbadri, M.E., Imam, Y.Z. and Gurbanna, B.A. (2010) Terlipressin-Induced Severe Left and Right Ventricular Dysfunction in Patient Presented with Upper Gastrointestinal Bleeding: Case Report and Literature Review. The American Journal of Emergency Medicine, 28, 540.e1-540.

[10] Wang, J. (2006) Electrochemical Biosensors: Towards Point-of-Care Cancer Diagnostics. Biosensors and Bioelectronics, 21, 1887-1892. http://dx.doi.org/10.1016/j.bios.2005.10.027

[11] Zhong, H., Yuan, R., Chai, Y., Li, W., Zhong, X. and Zhang, Y. (2011) In Situ Chemo-Synthesized Multi-Wall Carbon Nanotube-Conductive Polyaniline Nanocomposites: Characterization and Application for a Glucose Amperometric Biosensor. Talanta, 85, 104-111. http://dx.doi.org/10.1016/j.bios.2005.10.027

[12] Robles, T.F., Shetty, V., Zigler, C.M., Glover, D.A., Elashoff, D., Murphy, D., et al. (2011) The Feasibility of Ambulatory Biosensor Measurement of Salivary Alpha Amylase: Relationships with Self-Reported and Naturalistic Psychological Stress. Biological Psychology, 86, 50-56. http://dx.doi.org/10.1016/j.biopsycho.2010.10.006

[13] Li, W., Yuan, R., Chai, Y., Zhong, H. and Wang, Y. (2011) Study of the Biosensor Based on Platinum Nanoparticles Supported on Carbon Nanotubes and Sugar-Lectin Biospecific Interactions for the Determination of Glucose. Electrochimica Acta, 56, 4203-4208. http://dx.doi.org/10.1016/j.electacta.2011.01.095

[14] Zheng, B., Xie, S., Qian, L., Yuan, H., Xiao, D. and Choi, M.M.F. (2011) Gold Nanoparticles-Coated Eggshell Membrane with Immobilized Glucose Oxidase for Fabrication of Glucose Biosensor. Sensors and Actuators B: Chemical, 152, 49-55. http://dx.doi.org/10.1016/j.snb.2010.09.051

[15] Black, D. (1994) Familial Breast Cancer: BRCA1 down, BRCA2 to Go. Current Biology, 4, 1023-1024. http://dx.doi.org/10.1016/S0960-9822(00)00232-3

[16] Kumar, S.A., Cheng, H.W. and Chen, S.M. (2009) Electroanalysis of Ascorbic Acid (Vitamin C) Using Nano-ZnO/ Poly(Luminol) Hybrid Film Modified Electrode. Reactive and Functional Polymers, 69, 364-370. http://dx.doi.org/10.1016/j.reactfunctpolym.2009.03.001

[17] Jiang, L.C. and Zhang, W.D. (2009) A Highly Sensitive Nonenzymatic Glucose Sensor Based on CuO NanoparticlesModified Carbon Nanotube Electrode. Biosensors and Bioelectronics, 25, 1402-1407. http://dx.doi.org/10.1016/j.bios.2009.10.038

[18] Kong, T., Chen, Y., Ye, Y., Zhang, K., Wang, Z. and Wang, X. (2010) An Amperometric Glucose Biosensor Based on the Immobilization of Glucose Oxidase on the ZnO Nanotubes. Sensors and Actuators B: Chemical, 138, 344-350. http://dx.doi.org/10.1016/j.snb.2009.01.002

[19] Kilic, T., Topkaya, S.N., Ariksoysal, D.O., Ozsoz, M., Ballar, P., Erac Y., et al. (2012) Electrochemical Based Detection of MicroRNA, Mir21 in Breast Cancer Cells. Biosensors and Bioelectronics, 38, 195-201. http://dx.doi.org/10.1016/j.bios.2012.05.031

[20] Xu, X., Weng, X., Liu, A., Zhang, X., Wang, C., Chen, W., et al. (2013) An Electrochemical DNA Sensor for Detec- 
tion of Cytokeratin 19. Analytical Methods, 5, 2329-2334. http://dx.doi.org/10.1039/c3ay00037k

[21] Ali, S.M.U., Ibupoto, Z.H., Salman, S., Nur, O., Willander, M. and Danielsson, B. (2011) Selective Determination of Urea Using Urease Immobilized on ZnO Nanowires. Sensors and Actuators B: Chemical, 160, 637-643. http://dx.doi.org/10.1016/j.snb.2011.08.041

[22] Ali, S.M.U., Alvi, N.H., Ibupoto, Z., Nur, O., Willander, M. and Danielsson, B. (2011) Selective Potentiometric Determination of Uric Acid with Uricase Immobilized on ZnO Nanowires. Sensors and Actuators B: Chemical, 152, 241247. http://dx.doi.org/10.1016/j.snb.2010.12.015

[23] Chu, H.W., Thangamuthu, R. and Chen, S.M. (2007) Zinc Oxide/Zinc Hexacyanoferrate Hybrid Film-Modified Electrodes for Guanine Detection. Electroanalysis, 19, 1944-1951. http://dx.doi.org/10.1002/elan.200703966

[24] Ye, Y. and Ju, H. (2005) Rapid Detection of ssDNA and RNA Using Multi-Walled Carbon Nanotubes Modified Screen-Printed Carbon Electrode. Biosensors and Bioelectronics, 21, 735-741. http://dx.doi.org/10.1016/j.bios.2005.01.004

[25] Souza, E., Nascimento, G., Santana, N., Ferreira, D., Lima, M., Natividade, E., et al. (2011) Label-Free Electrochemical Detection of the Specific Oligonucleotide Sequence of Dengue Virus Type 1 on Pencil Graphite Electrodes. Sensors, 11, 5616-5629. http://dx.doi.org/10.1016/j.bios.2005.01.004 